\title{
Matrix Metalloproteinase 7 Measurement
}

National Cancer Institute

\section{Source}

National Cancer Institute. Matrix Metalloproteinase 7 Measurement. NCI Thesaurus.

Code C80195.

The determination of the amount of matrix metalloproteinase 7 present in a sample. 